\title{
If too frail, functional benefit following cardiac surgery may fail: A role for prehabilitation?
}

\author{
Jessica Forcillo, MD, MSc, ${ }^{a, b}$ and Louis P. Perrault, MD, $\mathrm{PhD}^{\mathrm{b}}$
}

\footnotetext{
From the ${ }^{\mathrm{a} C a r d i a c}$ Surgery Department, Centre Hospitalier de l'Université de Montréal; and ${ }^{\mathrm{b}}$ Cardiac Surgery Department, Montreal Heart Institute, Montreal, Québec, Canada.

Disclosures: Authors have nothing to disclose with regard to commercial support.

Received for publication Aug 23, 2017; accepted for publication Aug 26, 2017; available ahead of print Sept 22, 2017.

Address for reprints: Louis P. Perrault, MD, PhD, Department of Cardiac Surgery, Montreal Heart Institute, University of Montreal, 5000 Belanger St, Montreal, Québec H1T 1C8, Canada (E-mail: louis.perrault@icm-mhi. org).

J Thorac Cardiovasc Surg 2017;154:2000-1

$0022-5223 / \$ 36.00$

Copyright (c) 2017 by The American Association for Thoracic Surgery

http://dx.doi.org/10.1016/j.jtcvs.2017.08.088
}

The most common assessment tools for predicting early outcomes after cardiac surgeries have been the Society of Thoracic Surgeons predicted risk of mortality score and the European system for cardiac operative risk evaluation (EuroSCORE) II. ${ }^{1}$ Frailty has been defined as a geriatric biologic syndrome of increased vulnerability to environmental factors. The popularization of the use of frailty in our population of patients originated from the Cardiovascular Health Study ${ }^{2}$ and has been related to increased morbidity and mortality in individuals undergoing cardiac surgery. 3,4

The article by Lytwyn and colleagues ${ }^{5}$ evaluated the influence of adding 3 common definitions of frailty to the EuroSCORE II to predict functional survival 1-year after cardiac surgery. The authors ${ }^{5}$ showed that frailty was associated with an increased risk of decreased functional survival at 1 year (defined as being alive 1 year postsurgery and having an EuroQol-Visual Analogue Scale [EuroQol Research Foundation, Rotterdam, The Netherlands] [score > 60]) and improved risk prediction when added to the EuroSCORE II. This well-written study adds novel, clinically important information on functional survival after cardiac surgery.

The main measures of comparing model performance used by the authors were the integrated discrimination improvement and continuous net classification improvement (NRI). The significant difference does not translate into a clinically meaningful difference and may be overinterpreted. This is because continuous NRI does not consider the magnitude of desirable and undesirable changes in predicted risks; therefore, it may incorporate clinically irrelevant information and can make an uninformative marker to appear predictive. ${ }^{6}$ The NRI should have been presented based on some clinically meaningful risk categories. ${ }^{7}$ However, clinically meaningful categories of risk do not exist for functional survival. This well-conducted study includes selection bias, and we wonder what were the characteristics of the screened patients who refused the study and their reasons for doing so. Were the tests too burdensome? If so,

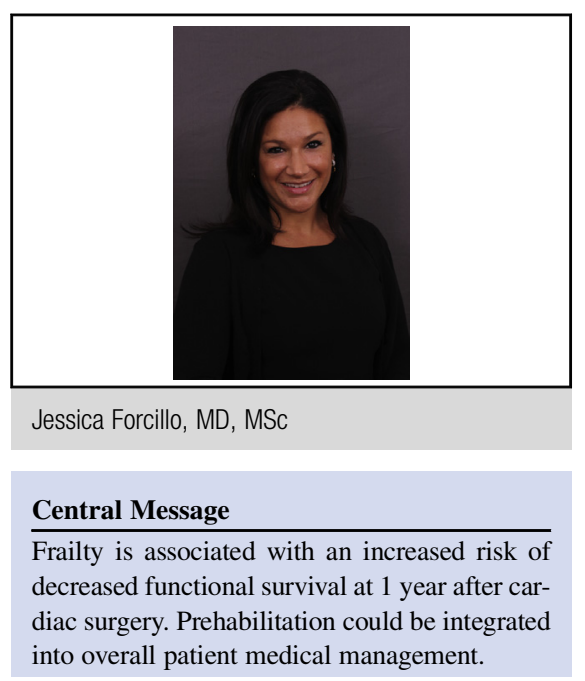

See Article page 1990.

robust patients were likely more agreeable to enrolling. Also, the time to complete all the assessments mentioned in this study is long (1-hour assessment appointment) and this is almost not applicable in a normal hospital setting. Among the components of the modified frailty criteria, slow gait speed and cognitive impairment were strong predictors of functional survival. Would it have been more clinically practical to simply administer a 5-m gait test? It was shown in the accompanying discussion that this test showed similar effectiveness as the comprehensive Fried criteria and Short Physical Performance Battery, which take a fraction of the time to complete. ${ }^{5}$ Albumin is also a biomarker of frailty, is associated with decline in functional performance, and is easy to obtain. ${ }^{8}$

Knowing who can be at risk of decreased function following cardiac surgery is, in our opinion, of utmost importance. This can lead to the development of a prehabilitation program. The effectiveness of this was recently studied in cardiac surgery ${ }^{9}$ and further studies are ongoing. It was indeed demonstrated that a cardiac prehabilitation program for patients waiting for elective coronary artery bypass surgery improved the walking distance and the gait speed compared with the no-prehabilitation program group and this benefit persisted up to 3 months following the surgery, resulting in better functional status of those individuals. ${ }^{10}$ Prehabilitation could be integrated into overall patient medical management. This can include preoperative refeeding and exercise 
programs and postoperative rehabilitation protocols. $^{11}$ Ongoing studies are currently investigating this.

\section{References}

1. Wendt D, Osswald BR, Kayser K, Thielmann M, Tossios P, Massoudy P, et al. Society of Thoracic Surgeons score is superior to the EuroSCORE determining mortality in high risk patients undergoing isolated aortic valve replacement. Ann Thorac Surg. 2009;88:468-74; discussion 474-5.

2. Buchner DM, Wagner EH. Preventing frail health. Clin Geriatr. Med. 1992;8: $1-17$.

3. Rockwood K, Mitnitski A. Frailty in relation to the accumulation of deficits. $J$ Gerontol A Biol Sci Med Sci. 2007;62:722-7.

4. Rockwood K, Mogilner A, Mitnitski A. Changes with age in the distribution of a frailty index. Mech Ageing Dev. 2004;125:517-9.

5. Lytwyn J, Tammers AN, Kehler DS, Jung P, Alexander B, Hiebert BM, et al. The impact of frailty on functional survival in patients 1 year after cardiac surgery. $J$ Thorac Cardiovasc Surg. 2017;154:1990-9.
6. Kerr KF, Wang Z, Janes H, McClelland RL, Psaty BM, Pepe MS. Net reclassification indices for evaluating risk prediction instruments: a critical review. Epidemiology. 2014;25:114-21.

7. Cook NR. Clinically relevant measures of fit? A note of caution. Am J Epidemiol. 2012;176:488-91.

8. Schalk BW, Visser M, Deeg DJ, Bouter LM. Lower levels of serum albumin and total cholesterol and future decline in functional performance in older persons: the Longitudinal Aging Study Amsterdam. Age Ageing. 2004;33: 266-72.

9. Furze G, Dumville JC, Miles JN, Irvine K, Thompson DR, Lewin RJ. “Prehabilitation" prior to CABG surgery improves physical functioning and depression. Int J Cardiol. 2009;132:51-8.

10. Sawatzky JA, Kehler DS, Ready AE, Lerner N, Boreskie S, Lamont D, et al. Prehabilitation program for elective coronary artery bypass graft surgery patients: a pilot randomized controlled study. Clin Rehabil. 2014;28:648-57.

11. Cabilan CJ, Hines S, Munday J. The effectiveness of prehabilitation or preoperative exercise for surgical patients: a systematic review. JBI Database System Rev Implement Rep. 2015;13:146-87. 